Gerd Fritz

COMPREHENSIBILITY AND THE BASIC STRUCTURES OF DIALOGUE

1. Introduction

2. Basic assumptions

2.1 The principle of comprehensibility: a dialogical principle

2.2 Some complicating factors in the application of the principle

2.3 Dialogical approach and cognitive approach

3. Aspects of understanding and types of comprehension problems

3.1 Level-generation and background of assumptions

3.2 Constellations of knowledge and their development

3.3 Local sequencing

3.4 Global sequences and alternative sequencing strategies

3.5 Structure and development of topics

3.6 Principles of communication

4. Dialogical comprehensibility experiments

4.1 Theory and methodology

4.2 An exploratory experiment

Notes

References

1. Introduction

The study of what makes utterances difficult or easy to understand is one of the central topics of research in comprehension. It is both theoretically attractive and useful in practice. The more we know about difficulties in understanding the more we know about understanding. And the better we grasp typical problems of understanding in certain types of discourse and for certain recipients the better we can overcome these problems and the better we can advise people whose job it is to overcome such problems. It is therefore not surprising that comprehensibility has been the object of much reflection as far back as the days of classical rhetoric and that it is a center of lively interest in several present-day scientific disciplines, ranging from artificial intelligence and educational psychology to linguistics. The multidisciplinary character of the field is no doubt.inspiring, but it does not 
make it easy to survey. Different approaches differ widely as to theoretical background, empirical methodology, and criteria of quality of research conducted in the respective traditions. The present paper aims at contributing to the geography of at least one region of this field by presenting an overview of what comprehensibility looks like from the position of linguistic communication analysis - or dialogue analysis, the label does not really matter. In order to bring out some of the basic ideas of this approach in full relief I shall now and then refer to a competitor (or ally?) in the field, which I shall summarily call "the cognitive approach". I shall begin by mentioning a few basic theoretical assumptions of the dialogical approach. From there I shall go on to discuss a theory-based list of comprehension problems, and finally, I shall raise a few questions as to experimental design in comprehensibility research.

\section{Basic assumptions}

2.1 The principle of comprehensibility: a dialogical principle In Grice's "Logic and conversation" we find the following remarks on the maxim of perspicuity, a close relative of the principle of comprehensibility: "... under the category of MANNER ... I include the supermaxim - 'Be perspicuous' - and various maxims such as:

1. 'Avoid obscurity of expression.'

2. 'Avoid ambiguity.'

3. 'Be brief (avoid unnecessary prolixity).'

4. 'Be orderly.'

And one may need others" (Grice 1967, II, 8). 1)

Although Grice quickly loses interest in this particular maxim the context of his statement may be useful as a starting point in order to locate the topic of comprehensibility within a theory of linguistic action. The principle of comprehensibility is one of the many principles of rational interaction. It is therefore basically a dialogical principle and should be treated accordingly. I should like to pursue this idea a little further, and in so doing, present a few arguments why a theory of dialogue ought to be one of the essential ingredients of comprehensibility research.

Comprehensibility is not just a quality of texts, as readability research generally assumed, but a quality of contributions to communicative transactions. A certain text may be easily comprehensible for one recipient but not for the other, therefore comprehensibility is largely a matter of "reci- 
pient design", i.e. the speaker or writer will base his decisions on how to say what he wants to say on his assumptions as to the competence, the assumptions, and the knowledge of the intended recipient. ${ }^{2)}$ Inversely, in understanding or interpreting the speaker's utterances the recipient will have to go on his or her assumptions as to the speaker's competence and assumptions. So what emerges is that in order to explain a phenomenon like "recipient design" we need concepts of a theory of dialogue, e.g. shared and non-shared knowledge, mutual assumptions, strategy (in a game-theoretical sense), just to name a few. It is furthermore important to see that comprehensibility is not the responsibility of the speaker or writer alone but something that depends on the contributions of the hearer or reader as well.

Seen from a practical point of view problems of comprehension are most urgent in types of communication that deviate from the face-to-face prototype of dialogue, e.g. written instructions, TV news broadcasts, lectures etc. This is due to the fact that these forms of communication show diverse limitations in the range of resources for locating and remedying comprehension troubles. (There are of course also certain advantages, like the chance to re-read a difficult written passage.) But even for these seemingly non-dialogical forms the dialogical prototype is a fundamental object of comparison. This is quite obvious in those cases where an author anticipates questions and objections from an imaginary audience and incorporates the relevant answers and refutations in his text. In some cases such practical measures actually consist in the adoption of dialogical procedures, e.g. the use of forms of dialogue in certain types of broadcast or of simulated dialogue in introductory passages of computer manuals or expert help systems (cf. Krenn 1989, Muckenhaupt 1986, Suchman 1987).

\subsection{Some complicating factors in the application of the principle} The application of the principle of comprehensibility is a fine-grained and highly context-bound matter. In this respect it resembles the application of the principle of relevance which is notoriously open-textured. In order to judge the proper status of the principle under discussion and in order to properly judge its modes of application one has to consider at least the following factors:

$$
\text { different types of discourse }
$$

For some types of discourse comprehensibility is a very high-level principle, e.g. in many types of instruction, where comprehensibility is a necessary condition of success. For other types of discourse it does not seem to be a 
fundamental principle at all, e.g. for the performance of some religious rituals or for the producing and reading of hermetic poetry. Even within an individual discourse the degree and mode of application may vary. Furthermore, the actual problems and possible measures of improvement of comprehensibility may vary with the type of discourse (e.g. career counselling vs. television news broadcasts).

$$
\text { different (kinds of) recipients }
$$

Small children, amnestic aphasics and first year students raise completely different problems of comprehension - at least superficially -, which one has to adapt to if one wants to reach certain communicative aims. There are also those cases where we deliberately violate the principle in order to exclude someone from parts of a dialogue, e.g. when talking about delicate topics "in front of the children". A special cluster of difficulties arises in situations where a speaker or writer addresses an inhomogeneous audience, as in the case of package inserts for medicine where often the same text addresses doctors and patients. Such compromise texts tend to be rather unsatisfactory as they are too difficult for laymen to understand and too uninformative for doctors. (iii) conflicts and connections with other principles

Depending on the type of discourse involved the principle of comprehensibility may conflict with the principle of brevity, the principle of complete information, the principle of precision, and others. The status of the principle in relation to a certain type of discourse also depends on the reasons one can give for following the principle. The analysis of such reasons often leads to principles of a different kind, like principles of efficiency (in many types of information transmission), basic democratic principles (as in legal contexts or in the case of political information in the media), principles of politeness, and others.

(iv) the current state of the discourse

In face-to-face communications problems of comprehension are usually dealt with in an ad-hoc fashion "as you go along". In doing so the participants can rely on their mutual knowledge which in part consists of their knowledge of the recent history of the discourse. ${ }^{3)}$ Knowledge of the dynamics of the discourse and its current state is an important resource for the location and repair of comprehension troubles. The problems involved are of a highly context-bound nature and seem to defy general prophylactic solutions in terms of rules and algorithms. 


\subsection{Dialogical approach and cognitive approach}

In order to show some areas of theoretical tension in the field I shall give a very rough description of two competing or, as I already mentioned, possibly complementary approaches to problems of comprehensibility. The two approaches I should like to compare could be called the dialogical or interactional approach and the cognitive approach. Of course, these two approaches are to a certain extent artifacts of my classification. I shall not comment on approaches with a mainly practical interest which do not seem to have any particular theoretical affiliation, like the so-called Hamburg conception, which is very popular in Germany, and the majority of readability formulas. ${ }^{4)}$

The dialogical approach is mainly represented by authors with a background from linguistics and/or discourse analysis (cf. Heringer 1979, Muckenhaupt 1981, Hoffmann 1984, Biere 1989). Some authors, like van Dijk, try to get the best of both worlds (cf. van Dijk/Kintsch 1983). As their theoretical creed interactionalist share some version of a theory of human action, more specifically a theory of linguistic action. Their method is to a certain extent phenomenological, i.e. one of their basic activities consists in the close description of utterance forms and contexts of use in which utterances tend to produce comprehension difficulties. At the same time they describe the interactive procedures that can be used to diagnose and clarify comprehension problems and the means normally used in securing comprehension. They explain comprehension difficulties in terms of the linguistic forms used, in terms of coherence relations (local sequencing, the dynamics of topic shift etc.) and the latitude involved in interpreting such relations, and in terms of knowledge constellations and the resources available for the solution of coordination problems.

The cognitive approach on the other hand is mainly represented by authors with a background from cognitive psychology or cognitive science in general. Of course there is no such thing as a unified position in this approach as well. The basic tenet of this approach is the assumption that understanding is an internal procedure by which an input of linguistic utterances is processed to yield an output of knowledge which is represented in the mind. The main activity of cognitivists consists in modelling aspects of this process and the types of representations involved. Explanations of comprehension problems are given in terms of processing load and memory capacity. Difficulties of comprehension show in an increase of processing time or a decrease in quantity or accuracy of recall. It is by looking at the mind of the individual that one can solve the puzzles of comprehension. 
Now if one feels that comprehensibility should be the subject of interdisciplinary studies one should try and find out if the cooperation could be put on a proper footing. This means submitting the respective conceptual frameworks to a close comparative scrutiny. In our case the comparison reveals quite a number of basic concepts where we might suspect divergence or even straight-on incompatibility. Among the major candidates are concepts like understanding, meaning, information, knowledge, strategy, and plan. ${ }^{5)}$ It is for example not obvious how understanding as an achievement concept (following Ryle's analysis) can be reconciled with the cognitivists' process model of understanding. If I say Now I understand what you mean I do not make a statement concerning internal processes but I rather describe a mental state. There is indeed a process concept which is related to the concept of understanding, namely interpreting. Interpreting is an activity which by steps of reasoning may lead from a first unsatisfactory understanding to a second, more adequate understanding. It is revealing that cognitivists rarely differentiate between understanding and interpreting. It is also quite difficult to determine the relationship between the concept of strategy used in game theory and the concept of strategy in cognitive psychology. It is rather instructive to see what a hard time van Dijk and Kintsch are having in explaining the compatibility of the two concepts (van Dijk/Kintsch 1983, 64ff.). On a lower and more technical level there are concepts like proposition. What is called a proposition by some cognitive psychologists looks very strange to someone trained in analytical philosophy or linguistics (cf. Kintsch/Vipond 1979). These rather too brief remarks indicate that there seems to be quite a bit of hard work to do before the two approaches may work in conceptual harmony. On the other hand there are promising signs of an increase in shared knowledge across the boundaries of the two approaches. The following passage by Marslen-Wilson and Tyler, two well-known representatives of the cognitive approach, could be taken as such a sign:

"In fact, we might speculate, it is the cooperativeness of speakers and listeners that goes the furthest in explaining how the speech process can be so rapid, and how, in particular, inputs can be projected with such immediacy onto the listener's discourse model: It is because speakers prepare their utterances so that they cohere with what has been said before, and because listeners run their processing systems on this assumption. This is what gives language processing its seemingly ballistic property - that the speaker constructs a communicative packet that is already configured to map onto the receptive configuration of the 
listener" (Marslen-Wilson/Tyler 1987, 61).

Discount the computer metaphors and you get one of the basic assumptions of the dialogical approach.

3. Aspects of understanding and types of comprehension problems The basic unit of understanding and misunderstanding, for a theory of linguistic action, is the linguistic act. A linguistic act is the use of a linguistic expression in a certain context and with a particular intention. I shall for the moment assume that problems connected with the concept of linguistic act (or speech act), speech act assignment, non-sentential utterance forms and similar questions can be solved. One of the lessons that can be derived from Wittgensteins use of the concept of Zusammenhang, which is a close relative of the concept of language game, is that it is the network of connections of a particular utterance that accounts for its function. ${ }^{6)}$ As a corollary for the theory of understanding one could formulate the slogan: "To understand an utterance is to see its connections". For this slogan to have any force one has to spell out what are the relevant connections (contexts, relations) which one has to see in order to understand. One would expect to find these connections among the basic principles of organization of discourse, especially dialogical discourse. I shall therefore list a number of connections that have received theoretical attention mainly during the last fifteen or twenty years and examine their relevance for comprehensibility. The guiding idea is that each of these connections represents an aspect of understanding and can therefore be taken as a factor which may play a role in comprehension problems. It will probably surprise nobody that in actual cases these factors interact, either cancelling out one another or producing a cumulative effect.

In what follows I shall deal only marginally with two topics that have always figured prominently in research on comprehensibility: vocabulary and syntax. This is merely a matter of emphasis in the present paper. ${ }^{7)}$ As far as syntax is concerned I should at least like to mention one interesting trend in studies on parsing. There is a growing body of research that seems to show that syntactic parsing relies to a considerable extent on contextual knowledge (cf. Crain/Steedman (1985) on the resolution of syntactic ambiguity). This is just one example of the interaction of factors. I shall also not deal with questions of pronunciation, intonation, speed of utterance, or, for that matter: lay-out in written texts, which are of course important factors of comprehensibility and which should be dealt with in a comprehensive treatment of the subject. 


\subsection{Level-generation and background of assumptions}

The first type of connection I shall consider has been well-known since the early days of speech-act theory, although it has not played a prominent role in Searle's version of a theory of speech acts. By uttering the same expression against different backgrounds of assumptions one can perform different speech acts, e.g. by uttering You started smoking again one can simply make a statement or, by making this statement, one can intend a more specific act like either an utterance of surprise or disapproval or both. This kind of relation between acts which was termed "level-generation" by Goldman (1970, 20 ) is an essential aspect of understanding. It is this relation that accounts for well-known facts like the following: People will understand the same utterance or sequence of utterances differently, they will sometimes misunderstand utterances to a certain degree and they will sometimes reach a different depth of understanding. The latter is a very interesting problem in teaching, for example.

To some psychologists this complex connection between different understandings of the same utterance seems to be nothing but an unwelcome complication for experimental design which is at the most grudgingly acknowledged but more readily ignored or explained away. From the point of view of dialogue analysis, however, this connection is both a fundamental resource and risk in communication, which shows up in the high proportion of preparation and clarification sequences in everyday conversations. The implications for comprehension research are obvious: The researcher should not just ask: "Did the subject understand the text?", meaning "Did she understand it the same way as the experimenter?", but rather one should ask: "How did she understand the text and what are the clues for this particular understanding?". Apart from a certain lack of hermeneutical imagination there is another characteristic of much psychological work that is related to this theoretical point. Researchers tend to neglect the illocutionary aspect of utterances as opposed to the propositional aspect. ${ }^{8}$ ) But very often a comprehension problem resides in the very difficulty of finding out whether a given utterance is to be taken as descriptive or as directive. This problem is, for example, quite frequent for users of instruction manuals (cf. Schäflein-Armbruster (forthcoming)).

\subsection{Constellations of knowledge and their development}

In part this second item is an extension of the first. It is a truism of philosophical communication theory that assumptions as to the knowledge and assumptions of the participants form one of the cornerstones of communication. 
As early as 1964 Strawson introduced the concept of identifying knowledge into the theory of reference. He also introduced two platitudes, as he called it, the principle of the presumption of ignorance and the complementary principle of the presumption of knowledge. Both principles are normally relied upon in informative discourse. In fact people commonly assume a large community of identifying knowledge and other relevant knowledge. The structure of such a constellation of knowledge has been spelt out by Schiffer (1972) and others, yielding the concept of mutual knowledge, an important if not undisputed concept of dialogue analysis. In the course of a dialogue a network of mutual knowledge and assumptions emerges, whether the participants aim at it or not. There are several mechanisms by which mutual assumptions arise. One of them comes into play when assumptions are presupposed for reference or for metaphorical speech which have neither been explicitly introduced nor can be assumed to be general knowledge. In this case the hearer might operate on the principle of accomodation, as Lewis (1979) called it. She will assume that the speaker takes certain facts as given and will herself take this for granted unless there is evidence to the contrary. In other cases, as for example in teaching communications, the participants may actually put a lot of effort into the systematic building-up of knowledge. Seen from the angle of comprehensibility the participants will have to answer questions like the following: Which is the relevant knowledge for an adequate understanding of individual instructional utterances? How does one know which is the relevant knowledge? (This concerns both teacher and pupil.) How can this knowledge be made available to the listener or reader? How does one find out what amount of knowledge listeners or readers already have available? How can one secure or activate this knowledge at relevant points in discourse? To what extent can the speaker or writer rely on inferences his partner in communication will draw? These questions point to a number of problems of coordination which have to be solved if communication is to be successful. In face-to-face dialogue there are, as we already mentioned, plenty of interactive resources for the solution of these coordination problems, whereas in written discourse knowledge management becomes a major difficulty. One important aspect of this difficulty is the question of adequate sequencing to which I shall revert in 3.4 .

The fundamental importance of knowledge management in communication is appreciated equally well by representatives of cognitive science and communication analysis. No doubt this is the major point of convergence between the different approaches in this field. Cognitive psychologists generally assume 
that the amount of non-stereotypical and not explicitly provided knowledge and the number of inferences needed for processing account for comprehension difficulties. If one does not accept the general processing model one will still come to similar conclusions by a different route of argument. As soon as normal first-pass understanding does not work on account of knowledge gaps the hearer or reader may have to turn to hermeneutic operations, and it is this predicament which is a symptom of comprehension problems.

Cognitive science has so far produced a number of interesting concepts like schema, frame and script which are useful first approximations to the kind of general knowledge a speaker can safely assume his hearer to possess if she is a member of a certain culture or society. These concepts are however rather rigid in view of the dynamics of knowledge accumulation and knowledge utilisation in communication. The analysis of the heuristic ad-hoc procedures which hearers and readers employ to cope with uncertainties in the attribution of knowledge and assumptions is still in its infancy.

\subsection{Local sequencing}

Local coherence has received a fair share of attention in recent studies on comprehension, with particular emphasis on problems of referential coherence (cf. Bower/Cirilo 1985, 86ff.). It is of course true that reference with its high degree of reliance on mutual knowledge looms large among comprehension problems. Furthermore, problems of reference are comparatively easily detected. And it is also true that there are special difficulties connected with cross-reference. But there is more to local coherence than cross-reference. Utterance $U_{1}$ may be used to make a statement, and the following utterance $U_{2}$ may be used to exemplify, prove, explain or otherwise support the statement. This sequence may presuppose various relations between the propositions expressed (entailment etc.). In other cases the first utterance may be intended to. prepare the second by providing a certain focus or a relevant item of knowledge etc. As these types of coherence relations have been dealt with in work on text linguistics and conversation analysis I shall not enlarge on this point (cf. Fritz 1982). Suffice it to say that the assignment of a sequence of utterances to an appropriate sequence pattern is an essential aspect of understanding and therefore also a frequent locus of comprehension problems. It is for example possible that a change of interpretation of one utterance in a sequence necessitates a reassessment of the meaning of the complete sequential neighbourhood. These subtle relations are often not sufficiently appreciated. This becomes apparent when researchers use 
scrambled texts for comprehension experiments (e.g. Thorndyke 1977). The scrambling usually does much more than just change the ordering of propositions.

\subsection{Global sequencing and alternative sequencing strategies}

For all types of extended discourse it is possible to differentiate characteristic substructures which often allow fairly intricate alternatives of sequencing. In problem-solving and planning dialogues, for example, one can present a suggestion, describe its ramifications, anticipate objections, compare it to alternative suggestions, and evaluate it. To a certain degree these segments of discourse are sequentially fixed. You cannot normally evaluate a suggestion that has not been made. But you can position descriptive elements at different points in the discourse. Therefore, as a speaker or writer you are faced with strategic choices of placement and as a hearer or reader you have to see the point of the chosen placement.

As far as research in comprehension is concerned there is mainly one type of discourse where global sequences have been extensively investigated, namely narrative discourse. There is also some work on expository texts, mainly from an educational point of view (cf. Schnotz 1984). The construction of so-called story grammars sparked off quite a lively discussion on global structures and their relation to understanding. Generally speaking, these studies, especially the early ones (cf. Rumelhart 1975), tend to underrate the variability of placement of typical story segments. As a consequence story grammarians underrate the flexibility of hearers and readers in dealing with sequencing alternatives, but also the type of comprehension problem that lies in this variability.

I should like to illustrate the difficulties involved by describing informally some global sequencing alternatives and their consequences for a type of discourse, that has been investigated by linguists, among others, namely teaching how to play a game (cf. Muckenhaupt 1976). In teaching how to play a game like chess you can first introduce and describe the complete inventory of game objects, i.e. the chessboard and the pieces, and then go on to describe all the individual kinds of moves one can make with the different types of chessmen. You can then attend to matters of strategy and so on. The advantage of this kind of "systematic" introduction will be that the learner receives a general idea of what the game is about at an early stage of his tuition. On the other hand it is quite likely that our learner will have forgotten most of the general information by the time he is supposed to 
make his first move. If you suspect this possibility you might prefer providing information as you go along on the principle of "need to know". You might start by introducing a pawn, describing its range of movement and giving the learner a short exercise in following these simple rules. You then continue by introducing a knight in the same fashion etc. For some learners this method of spacing-out information will increase the comprehensibility of individual explanations, as the relevance of each bit of information becomes immediately recognizable. However, some learners might resent this kind of spoon-feeding. There are of course also particularly confusing mixed strategies where the teacher jumps back and forth between the introduction of game pieces, strategic hints, rule formulations and reminiscences of interesting games.

Now obviously this question of strategic placement of certain types of linguistic act applies not only to the teaching of games but also to other kinds of instruction and to many other types of discourse.

In concluding this point I should like to mention the question of explicitness to which I shall revert in section 3.6. In the present context the question takes the following form: What is the relative merit of just using an optimal placement strategy - if there is one - and of actually telling the hearer/reader which strategy you are using?

\subsection{Structure and development of topics}

As a global principle of organization of discourse topical sequencing is complementary to functional (or illocutionary) sequencing which I dealt with in the last two sections. It is an important part of comprehension to keep up with the development of the topic or topics. As with illocutionary force there is a fairly complex relationship between the actual utterances and what they are about. A passage of discourse may at first sight be about different means of transport, like cars, lorries, airplanes, buses, trains and bycicles. On closer inspection it really turns out to be about the topic of ecology. One could describe this as a kind of topical "level-generation": By talking about cars and bycicles etc. in a certain way one can talk about ecology. So at this point we again find the systematic problem of depth of understanding as well as the problem of differing understandings concerning the current topic. If a listener or reader does not realize the superordinate topic of a passage of discourse he may well find it difficult to see connections between parts of this passage. He may interpret the topical development as a case of topic change instead of taking it as a change of aspect within 
the same topic. In other words: If one wants to keep one's listener or reader up to date as to the topical state of the discourse it might be useful to indicate the structure of the topical network as the speaker or writer sees it.

These assumptions will probably not be disputed by anyone, but in mainstream comprehensibility research these questions are still underrepresented. There is indeed an increasing number of studies on topic structure, topic continuity, and topic shift (e.g. Fletcher 1984, Garrod/Sanford 1983, Lorch et al. 1985) but much of the rich knowledge on topic introduction, topic change, topic shading etc. which has been accumulated in conversation analysis and text linguistics (e.g. Schegloff/Sacks 1973, Bublitz 1988) still awaits application in empirical research on comprehensibility.

\subsection{Principles of communication}

As with other aspects of communication, like functional sequencing and topic management, principles of communication may become relevant at two different levels. At the basic level principles may be followed in order to safeguard the attainment of communicative aims. At the secondary level they may actually be mentioned in order to secure mutual knowledge of what is going on. For example, in giving an introductory lecture course to beginners a lecturer might announce that the first lecture will give a general idea of the topic in everyday language, whereas the second lecture will increase the degree of detail and terminological precision. This announcement will help the student to understand what is going on in the transition from lecture one to lecture two and to appreciate the respective style of presentation. Knowing the principles somebody is acting on supplies a basis for recognizing his intentions and, if necessary, for figuring out what these intentions could be if they are not obvious.

I shall in this paper not tackle the principle of relevance which is of course all-pervasive in matters of understanding (cf. Dascal 1979, Sperber/ Wilson 1986). In fact, the types of connections I have mentioned so far could be considered as a partial explication of the concept of communicative relevance. I shall however present a few reflections on another principle which is also prominent in the field of comprehension, namely the principle of explicitness. Explicitness is generally assumed to be the cure for many maladies of comprehension. But this has to be taken with a grain of salt.

In everyday informal dialogue many things are left implicit. Speakers rely on their hearers' being alive to the current state of the dialogue and 
therefore assume that the nature of their speech acts, speech act sequences, topical connections etc. will be apparent without further comment. It is important to see that this is not a weakness but a fundamental resource of efficient discourse. Now if one aims at a high level of complexity and depth of understanding one might seek extra measures to make sure one gets across what one wants to be understood. One of these measures is the increase of explicitness. One type of application of the principle of explicitness is the use of reflexive moves, i.e. naming the function or topic of a passage, announcing a change of topic, summarizing the gist of what one intended to say etc. These measures can be taken in advance, afterwards or even simultaneously - if one can use pictures, graphic displays or marginalia. All this is uncontroversial and in good consonance with results from cognitive psychology, e.g. the concept of "advance organizer" (cf. Ausubel 1960). There is however a limit to explicitness. Total explicitness is not possible on principle as there is no utterance which does not rely on a background of assumptions. And a very high degree of explicitness conflicts with the principles of brevity, simplicity and continuity of topic. So, in fact, explicitness may be self-defeating. The secret is to provide explicitness in the right places. In some cases it is possible to give general guidelines how to apply the principle, as in the case of instructional texts where one can follow a principle of decreasing explicitness. For any new topic, introductory passages are to be highest in explicitness. If the presentation of knowledge is well-controlled, explicitness can be systematically reduced in later passages. But generally speaking, to decide which are the salient points which have to be made explicit is a matter of judgement and cannot be predetermined in a completely mechanical fashion. It needs the kind of expertise that is gained by experience with specific types of discourse and specific recipients. Of course we assume that it is theoretically enlightened experience which will be most explicit in its judgment.

4. Dialogical comprehensibility experiments

\subsection{Theory and methodology}

Empirical research on comprehensibility serves a variety of purposes from justifying theories of comprehension to testing and improving the usability of particular texts for particular users. Of the many relevant questions that could be dealt with at the present stage of research there is one that seems particularly attractive, as it points both ways, towards the construction of theories and towards the solution of practical problems. This is 
the question of a typology of comprehension problems - or a family of typologies - that is/are both theoretically sound and practically relevant. One would expect that it should be possible to give a medium-sized list of basic problem-types which could be traced back to basic aspects of the understanding of communicative acts. That is what I provisionally attempted in the preceding sections. It is however a remarkable experience that types of problems tend to proliferate as soon as one closely analyses particular types of discourse. A case in point is the plethora of new problems that show up if one starts to analyse the uses of pictures and graphical elements in addition to the use of linguistic expressions. So for the time being it looks like a good strategy to combine a theoretical interest with detailed exploration of particular types of discourse.

A particular type of theory usually also favours a particular methodology. This is true for the dialogical approach which calls for a more dialogical methodology than what is customary in traditional psychological experiments. Without going into technical detail one can trace back the basic methodological decisions in this field to the question of which are reliable criteria of understanding and which are reliable indicators of comprehension problems. In everyday communication the fundamental criterion of understanding is a communicative one. If $B$ is able to produce a relevant reaction to $A$ 's utterance $A$ will generally accept that $B$ understood $A$ 's utterance the way she meant it. This is a truly dialogical criterion, as $A$ is in the same situation as $B$, i.e. the situation of having to understand what the other participant meant by her utterance. There is not way out of this hermeutical predicament. What is interesting from the point of view of experimental methodology is that the spectrum of reactions that could count as relevant reactions is vast. Types of relevant reactions include: answering a question, following a directive, questioning a presupposition, contradicting a statement, correcting a description, asking if a given paraphrase is correct, asking if the preceding discourse really was about such and such a topic, continuing a narrative at a certain point etc. It is remarkable that traditional psychological methods relied on a very small inventory of criteria, mainly recall (free recall and cued recall). As for the indicators of comprehension problems similar things can be said. Types of relevant reactions include: giving an answer to a question that was not asked, not following the directzve, following a directive that was not given, hesitating in following the directive, asking for clarification, asking for repetition, complaining about the speed of utterance, re-reading a written passage, starting to 
read aloud a difficult passage, going back to a passage where a related topic was dealt with etc. Again the traditional inventory of indicators comprises a relatively small selection, including reading times, reaction times and eye movements. In recent times the traditional behavioral experiments for the measurement of comprehensibility seem to have lost some of their attraction even within the community of psychologists. Experiments that collect reading times, recall protocols, eye movements and reaction times are not considered "sufficiently rich and distinctive for discovering the complex symbolic mechanisms and representations that are involved" (Graesser/Robertson/Clark 1983, 62). However, other methods, like question-answering, reading aloud and thinking aloud, are still considered rather "soft" methods the reliability and validity of which is doubtful. It is however conceded that these methods are heuristically valuable. It looks as if at the present stage of comprehensibility research the generation of interesting hypotheses is such an important desideratum that heuristic methods are called for, even if they do not stand up to classical standards of psychological research. Without belittling the methodological problems involved one could generally advocate a shift of interest from statistical sophistication to interpretive finesse. The main problems of dialogical methods seem to lie in two characteristics which one has to come to terms with: In the first place, spontaneous reactions of the subjects are not easily standardized. Secondly, using a rich inventory of criteria and indicators forces the experimenters to a rather time-consuming amount of interpretive work. Both objections should not be made light of. But one would hope that what dialogical experiments lose in classical elegance they gain in ecological validity.

\subsection{An exploratory experiment}

In order to give these reflections some more vividness, I shall now present a few preliminary remarks on a small-scale exploratory experiment we did in Tübingen in April 1990. ${ }^{9}$ ) The primary aim of the experiment was to get empirical data concerning comprehension problems which we expected beginners to have with the introductory passages of an experimental software manual. We had formed these expectations on the basis of a close analysis of these passages and on the basis of an earlier pre-test with different versions of such passages. The test setting was as follows:

The subject is seated at the computer with the manual placed next to the keybord. The subject is told to read aloud the manual text and to follow the instructions given. She is also told to volce any comments that come to her mind 
concerning the text or her own execution of the instructions. Next to the subject the experimenter takes place. He has a double function. He may be asked by the subject to help her with any problem that comes up in the course of the procedure. And he himself has a prepared list of questions, formulated on the basis of the prior analysis, which he can ask if he feels that the subject has problems she herself does not notice or does not consider worth mentioning.

The whole procedure is recorded on videotape with two video cameras in order to get a good view of the screen and keyboard as well as the subject and the experimenter.

The design of the experiment yields a rich combination of criteria of understanding and indicators of comprehension problems. In the first place, we have the external criterion of success in the manipulation of the computer. There are also other criteria of successful understanding, e.g. correct commentaries on what was to be achieved by a certain passage. Secondly, we find behavioral indicators like direction of gaze, hesitation, slowing down in reading speed etc. Thirdly, we find problem-solving strategies like re-reading passages, jumping back and forth between the passage under work and earlier paragraphs, checking and re-checking the relation between graphics in the manual and what is on the screen. A fourth group are communicative indicators like rising intonation to convey doubt, calls for help and statements as to the problems the subject encounters. Finally, we have the answers to the experimenter's questions, which provide information as to unexpected understandings, misunderstandings and lack of knowledge at certain points in the procedure. Of course the richness of indicators may be considered a mixed blessing if one thinks in terms of experimental economy. But economy was at this point no high-ranking demand.

This little experiment is fairly unsophisticated in several respects and it would surely meet with many objections from experimental psychologists. But as a heuristic device it turned out to be highly useful. In many cases indicators consistently pointed towards the problems we had predicted on the basis of our analysis. Apart from confirming a number of hypotheses the experiment contributed to the development of a more specific typology of comprehension problems for the users of this particular text. These were mainly difficulties related to the types of problems mentioned earlier in this paper, e.g. unfamiliar terminology that was not properly introduced, inconsistent nomenclature, awkward syntactic structures (complex and ambiguous sentences), problems of reference and of unsatisfactory sequential organization, problems with the function of individual sentences, passages, and graphics, problems with the relations between text and graphics etc. On the other hand quite a number of difficulties 
arose which we had not anticipated and which could in part be put down to particular reading strategies we had not expected. In general, we found it remarkable how patient the subjects dealt with fairly bad passages. They mostly adopted a wait-and-see strategy and applied the principle of charity. This was also an interesting result.

In concluding this paper I should like to draw attention to a difficulty which is inherent in any kind of empirical experiment in this field but which becomes magnified with the richness of indicators available in our case. It is one thing to note a certain utterance or action as an indicator of trouble but quite another to attribute the trouble with sufficient confidence to one particular factor or a particular set of factors. This difficulty is less grave if one is mainly interested in practical matters, i.e. in the improvement of the manual in question. In this case the location of an area of trouble usually suffices to suggest improvements. If however one is interested in correlating indicators with types of problems in a principled way things become much more complicated. This is mainly due to two facts: First of all, in many cases different potential factors are simultaneously present, e.g. an unfamiliar metaphorical use of an expression and lack of relevant knowledge, which poses the analytical task of filtering out which individual factor or which interplay of factors actually caused the trouble. Ideally one would have to vary textual characteristics and knowledge structures in such a fashion as to allow one to isolate individual factors or the relevant cluster of factors. Secondly, particular indicators, like hesitation, re-reading etc., may point to different factors, e.g. a difficult syntactic construction or an unclear relation between text and graphic. In the latter case we would expect eye movement to give a further hint. But in many cases there are no obvious differentiating indicators available. Some of the indicators are more specific than others. Explicit complaints or questions are highest in the scale of direct indication. But even so, complaints are no analyses. If a subject complains that after reading a sentence she does not know whether she is now expected to do something or whether the machine will now "do" something, this complaint does not show whether the real problem lies in the fact that by using a sentence in the passive voice the author does not specify the agent of the relevant activity or in the fact that the author has done nothing to clarify the nature of the activity in the previous text or in the combination of facts. This, by the way, is one of the reasons why expert ratings are no substitute for principled analysis. A rating like "confusing" does nothing to pinpoint the relevant factors. An indicator like the subject's turning back the pages in the text is a fairly good 
indicator that the subject lacks a particular bit of information which she believes was presented at an earlier point in the instruction. But it is the kind of indicator where one might want to actually ask the subject what it is she is looking for. It takes an attentive experimenter not to miss such opportunities for clarification. It looks as if hesitation, slowing down etc. were the least specific indicators which do in general not yield more than unspecific evidence of trouble. This is the point where a detailed analysis of the context of the trouble has to set in.

In sum, the experiment contains two levels of detailed analysis, which could be explained as concerning two moves of a dialogue game. The first analysis concerns the structure of the text which is intended to be used as a first move (or sequence of moves) in the instruction game. This analysis aims at generating hypotheses as to problems of comprehension which are related to types of factors and clusters of factors provided by dialogue theory. The second analysis concerns the reactions of the subjects, i.e. the second moves in the instruction game. Again the focus of analysis is provided by the theoretical framework. The second analysis concentrates on potential indicators, their context and their relations with comprehension factors. If this looks like a rather complicated set of interpretive procedures, the complications are germane to the subject.

In winding up this paper I should like to give a short programmatic summary. The dialogical (or interactionist) approach presented in this paper emphasizes aspects that have so far been underrated, e.g. recipient design of utterances, patterns of functional sequencing and strategic sequencing alternatives. It provides tools for dialogical experimental design and a fine-grained and contextsensitive analysis of dialogues and their monological counterparts, which includes a sophisticated interpretive methodology for experimental data. It would seein that serious theorizing on internal cognitive processes would have to be based on a detailed analysis of what the processing models are supposed to explain. Therefore an emphasis on detailed analysis of dialogical action will no doubt make sense to cognitivists as well. On the other hand, pending the clarification of some of the conceptual matters mentioned in section 2.3, an agnostic attitude as to the assumptions of particular processing models could be considered a consistent attitude for an interactionist. 
Notes

1) Grice's remarks are a distinct echo of a precept of classical rhetoric, i.e. that our prime virtue in speech should be perspicuity.

2) The concept of recipient design goes back to Sacks/Schegloff/Jefferson (1974).

3) On the analysis of dialogue dynamics and the history of dialogue cf. Fritz (1989).

4) The Hamburg conception is presented in Langer/Schulz v. Thun/Tausch (1981). A critical assessment of the Hamburg conception and of readability formulas can be found in Ballstaedt/Mandl (1988). A critical attitude do readability formulas is also the general tendency in the papers collected in Davison/ Green (1988).

5) Space does not permit a detailed analysis of the concepts in question. Fritz (1991) contains some further reflections on the concepts of plan and of understanding. Suchman (1987) contains a very insightful discussion of the basic assumptions of interactionalists and cognitivists. Cf. also Biere (1989) .

6) Cf. Wittgenstein (1969), §§ 347ff.

7) A useful book on syntax and comprehension is Heringer (1988), a "receptive grammar" of German.

8) The emphasis on the propositional aspect often goes hand in hand not only with the neglect of the illocutionary aspect but also with a disregard for the syntactic form of utterances. Both shortcomings are evident in van Dijk/ Kintsch (1983), in spite of avowals to the contrary.

9) A detailed report on this experiment will be given in Schäflein-Armbruster (forthcoming).

\section{References}

Ausubel, D.P. (1960), The use of advance organizers in the learning and retention of meaningful verbal material. In: Journal of Educational Psychology $51,267-272$.

Ballstaedt, S.-P./Mandl, H. (1988), The assessment of comprehensibility. In. Ammon, U./Dittmar, N./Mattheier, K.J. (eds.), Sociolinguistics. An international handbook of the science of language and society, Berlin/New York, 1039-1052.

Biere, B.U. (1989), Verständlich-Machen. Hermeneutische Tradition - Historische Praxis - Sprachtheoretische Begründung, Tübingen.

Bower, G.H./Cirilo, R.K. (1985), Cognitive psychology and text processing. In: van Dijk, T.A. (ed.), Handbook of discourse analysis. Vol. 1, London, 71105.

Bublitz, W. (1988), Supportive fellow-speakers and cooperative conversations, Amsterdam/Philadelphia.

Crain, S./Steedman, M. (1985), On being led up the garden path: the use of context by the psychological syntax processor. In: Dowty, D.R./Karttunen, L./ Zwicky, A.M. (eds.), Natural language parsing. Psychological, computational, and theoretical perspectives, Cambridge, 320-358.

Dascal, M. (1979), Conversational relevance. In: Margalit, A. (ed.), Meaning and use, Dordrecht, 153-174. 
Davison, A./Green, G.M. (1988) (eds.), Linguistic complexity and text comprehension. Readability reconsidered, Hillsdale, N.J.

van Dijk, T.A./Kintsch, W. (1983), Strategies of discourse understanding, New York/London.

Fletcher, C.R. (1984), Markedness and topic continuity in discourse processing. In: Journal of Verbal Learning and Verbal Behavior 23, 487-493.

Fritz, G. (1982), Kohärenz. Grundfragen der linguistischen Kommunikationsanalyse, Tübingen.

Fritz, G. (1989), Zur Beschreibung der Dialogdynamik. Plädoyer für eine kommunikationshistorische Beratungsweise. In: Weigand, E./Hundsnurscher, F. (Hrsg.), Dialoganalyse II, Bd. 1, Tübingen, 19-32.

Fritz, G. (1991), Philosophy of language and communication theory. In: Dascal, M./Lorenz, K./Meggle, G. (eds.), Philosophy of language. A handbook, Berlin/ New York.

Garrod, S./Sanford, A. (1983), Topic dependent effects in language processing. In: Flores d'Arcais, G.B./Jarvella, R.J. (eds.), The process of language understanding, Chichester/New York.

Goldman, A.I. (1970), A theory of human action, Englewood Cliffs, N.J.

Graesser, A.C./Robertson, S.P./Clark, L.F. (1983), Question-answering: A method for exploring the on-line construction of prose representations. In: Fine, J./Freedle, R.O. (eds.), Developmental issues in discourse, Norwood, N.J., 41-68.

Grice, H.P. (1967), Logic and conversation. The William James Lectures (Typescript).

Heringer, H.J. (1979), Verständlichkeit - ein genuiner Forschungsbereich der Linguistik? In: Zeitschrift für germanistische Linguistik 7, 255-278.

Heringer, H.J. (1988), Lesen lehren lernen. Eine rezeptive Grammatik des Deutschen, Tübingen.

Hoffmann, L. (1984), Mehrfachadressierung und Verständlichkeit. In: Zeitschrift für Literaturwissenschaft und Linguistik 55, 71-85.

Kintsch, W./Vipond, D. (1979), Reading comprehension and readability in educational practice and psychological theory. In: Nilsson, L.G. (ed.), Perspectives on memory research, Hillsdale, N.J.

Krenn, M. (1989), Leserbezug und dialogische Techniken in Softwarehandbüchern. In: Weigand, E./Hundsnurscher, F. (Hrsg.), Dialoganalyse II, Bd. 2, Tübingen, 347-360.

Langer, I./Schulz v. Thun, F./Tausch, R. (1981), Sich verständlich ausdrücken, München/Basel.

Lewis, D. (1979), Scorekeeping in a language game. In: Journal of Philosophical Logic 8, 339-359.

Lorch, R.F./Lorch, E.P./Matthews, P.D. (1985), On-line processing of the topic structure of a text. In: Journal of Memory and Language 24, 350-362.

Marslen-Wilson, W./Tyler, L.K. (1987), Against modularity. In: Garfield, J.L. (ed.), Modularity in knowledge representation and natural language understanding, Cambridge, Mass./London.

Muckenhaupt, M. (1976), Spiele lehren und lernen, Tübingen.

Muckenhaupt, M. (1981), Verstehen und Verständlichkeit. Vorschläge zu einer kom- 
munikativen Analyse der Verständlichkeit und des Zusammenhangs von Text und Bild. In: Kodikas/Code 3, 39-81.

Muckenhaupt, M. (1986), Text und Bild. Grundfragen der Beschreibung von TextBild-Kommunikationen aus sprachwissenschaftlicher Sicht, Tübingen.

Rumelhart, D.E. (1975), Notes on a schema for stories. In: Bobrow, D.G./Collins, A. (eds.), Representation and understanding: Studies in cognitive science, New York, 211-236.

Ryle, G. (1949), The concept of mind, London.

Sacks, H./Schegloff, E.A./Jefferson, G. (1974), A simplest systematics for the organization of turn-taking in conversation. In: Language 50, 696-735.

Schäflein-Armbruster, R. (forthcoming), Verständlichkeit und Wissensvermittlung in Gebrauchstexten, (Doctoral Diss.) Tübingen.

Schegloff, E.A./Sacks, H. (1973), Opening up closings. In: Semiotica 8, 289-327.

Schiffer, S. (1972), Meaning, Oxford.

Schnotz, W. (1984), Comparative instructional text organization. In: Mandl, H./ Stein, N.L./Trabasso, T. (eds.), Learning and comprehension of text, Hillsdale, N.J., 53-81.

Sperber, D./Wilson, D. (1986), Relevance: Communication and cognition, Oxford.

Strawson, P.F. (1964), Identifying reference and truth-values. In: Theoria 30, 96-118.

Suchman, L.A. (1987), Plans and situated action, Cambridge.

Thorndyke, P.W. (1977), Cognitive structures in comprehension and memory of narrative discourse. In: Cognitive Psychology 9, 77-110.

Wittgenstein, L. (1969), On certainty, ed. Anscombe, G.E.M./von Wright, G.H., Oxford. 


\section{Dialoganalyse III}

Referate der 3. Arbeitstagung

Bologna 1990

Herausgegeben von

Sorin Stati, Edda Weigand und

Franz Hundsnurscher

Teil 1

Max Niemeyer Verlag

Tübingen 1991 